\title{
POLA DISTRIBUSI NYERI ALIH DAN POSISI TUBUH PENCETUS NYERI SENDI SAKROILIAKA
}

\author{
REFERRAL PAIN DISTRIBUTION PATTERN AND TRIGGERING POSITION \\ OF SACROILIAC JOINT PAIN
}

Yusak Mangara Tua Siahaan, * Vivien Puspitasari, *Vinson Hartoyo*

\section{ABSTRACT}

Introduction: Sacroiliac joint (SIJ) contribution to cause low back pain is still widely debated. SIJ is hardly distinguished from facet joint pain or other musculoskeletal disorder causing low back pain and leads to diagnostic difficulties. There are several factors that contribute to SIJ pain diagnosis, which are referral pain area and triggering position.

Aim: To investigate the distribution pattern of referral pain and position that could trigger the sacroiliac joint pain.

Method: Patients with complaints of pain in buttock area and diagnosed as SIJ pain by intra articular block diagnostic test at Neurology Clinic of of Siloam Hospitals Lippo Village between August to December 2017 were interviewed to record the area of referral pain and position which triggered the pain.

Results: 114 subjects with complaint of buttock pain, ratio between men and women was 1:2.35 ( $n=34$ and 80), were included in this study. Posterior compartment of the thigh $(19.3 \%, n=22)$ is the most common referral pain area followed by lateral part of the thigh $(11.4 \%, n=13)$. Getting up from sitting position and long period of sitting were the two most dominant factors that could trigger pain $(61.4 \%, n=70$ and $49.1 \%, n=56)$.

Discussion: The referral pain distribution pattern of sacroiliac joint pain was dominated by the posterior part and lateral part of thigh, while getting up from sitting and long period of sitting is found in majority of the subjects as the most dominant triggering position.

Keywords: Pain pattern, sacroiliac joint pain, triggering position

\section{ABSTRAK}

Pendahuluan: Kontribusi nyeri sendi sakroiliaka sebagai penyebab nyeri pinggang masih menjadi perdebatan. Secara klinis, nyeri sendi sakroiliaka sulit dibedakan dengan nyeri sendi faset lumbal maupun gangguan muskuloskeletal lainnya sehingga menyulitkan dalam diagnosis. Terdapat faktor yang memengaruhi terjadinya nyeri sendi sakroiliaka antara lain posisi tubuh yang mencetuskan nyeri dan area nyeri alih yang menyertainya.

Tujuan: Untuk mengetahui pola distribusi nyeri alih dan faktor posisi tubuh yang mencetuskan atau memperberat nyeri sendi sakroiliaka.

Metode: Pasien yang datang dengan keluhan nyeri bokong yang terdiagnosis mengalami nyeri sendi sakroiliaka berdasarkan tes diagnostik injeksi blok intraartikular di poliklinik saraf RS Siloam Lippo Village dalam rentang waktu Agustus-Desember 2017 dilakukan wawancara untuk mengetahui area nyeri alih dan posisi pencetus nyeri.

Hasil: Sebanyak 114 pasien dengan keluhan pada area bokong, rasio antara laki-laki dan perempuan dengan perbandingan 1:2,35 ( $\mathrm{n}=34$ dan 80$)$ diikutsertakan dalam studi ini. Paha bagian posterior merupakan area nyeri alih terbanyak $(19,3 \%, \mathrm{n}=22)$ diikuti area paha lateralis $(11,4 \%, \mathrm{n}=13)$. Sedangkan posisi tubuh yang paling dominan memicu timbulnya nyeri sendi sakroiliaka adalah posisi bangun dari duduk $(61,4 \%, n=70)$ dan duduk lama $(49,1 \%, n=56)$.

Diskusi: Pola distribusi nyeri alih pada pasien nyeri sendi sakroiliaka yang paling banyak ditemukan adalah nyeri pada daerah paha sisi posterior dan paha sisi lateral sedangkan faktor yang paling dominan mencetuskan atau memperberat nyeri sendi sakroiliaka adalah posisi bangun dari duduk dan posisi duduk yang lama.

Kata kunci: Nyeri sendi sakroiliaka, pola nyeri, posisi tubuh pencetus

*Departemen Neurologi FK Universitas Pelita Harapan/RS Siloam Lippo Village, Tangerang. Korespondensi: dryusaks2002@gmail. com.

\section{PENDAHULUAN}

Nyeri sendi sakroiliaka merupakan nyeri yang dirasakan pada area sendi tersebut yang dapat menjalar hingga ke daerah inguinal, bokong, hingga area paha posterior. Berdasarkan studi yang dilakukan oleh Gupta dkk, sebanyak 10-25\% kasus nyeri pinggang mekanis yang menetap berhubungan dengan gangguan pada sendi sakroiliaka. ${ }^{1}$ Nyeri sendi sakroiliaka seringkali salah didiagnosis sebagai nyeri akibat hernia nukleus pulposus, nyeri sendi faset, atau nyeri akibat spasme otot-otot paravetebra maupun panggul.

Hal tersebut dimungkinkan karena secara klinis maupun perjalanan penyakitnya nyeri sendi 
sakroiliaka sulit dibedakan dengan nyeri sendi faset lumbal maupun gangguan muskuloskeletal lainnya sehingga menyulitkan dalam diagnosis. Ketidaktepatan diagnosis menyebabkan ketidaktepatan penatalaksanaan nyeri sehingga mengakibatkan disabilitas aktivitas penderita yang bertambah panjang. ${ }^{2-3}$ Pada kenyataannya, nyeri sendi sakroiliaka tidak memiliki riwayat perjalanan penyakit yang jelas, pemeriksaan fisik maupun radiologis yang secara definit dapat menegakkan diagnosis nyeri sendi sakroiliaka.

International Association for the Study of Pain (IASP) menyusun 3 kriteria dalam mendiagnosis nyeri sendi sakroiliaka, yang salah satunya adalah hilang atau berkurangnya nyeri melalui blok anestesi, yang disebut juga diagnostic block. Tindakan tersebut memiliki sensitivitas dan spesifisitas yang paling tinggi, sehingga dijadikan sebagai referensi saat ini. Pemeriksaan radiologis seperti MRI, CT scan, ultrasonografi, atau x-ray juga menjadi pilihan untuk mendiagnosis nyeri sendi sakroiliaka, namun tingkat sensitivitasnya lebih rendah dan tidak spesifik dalam mendeteksi proses inflamasi dibandingkan dengan blok diagnostik.

Pemeriksaan radiologis hanya dilakukan pada pasien dengan riwayat trauma berat atau terdapat gejala klinis untuk sakroilitis. Perubahan yang didapatkan pada pemeriksaan radiologis juga sering kali bersifat asimtomatik, sehingga diagnosis nyeri sendi sakroiliaka tetap dapat ditegakkan meski tanpa kelainan radiologis. ${ }^{4-5}$

Faktor lainnya yang dapat membantu menunjang diagnosis nyeri sakroiliaka adalah posisi tubuh yang mencetuskan dan memperberat nyeri serta pola area nyeri alih yang menyertai nyeri. Terdapat beberapa posisi tubuh yang mencetuskan nyeri tetapi belum ada penelitian yang mendalami posisi tubuh tersebut. Nyeri alih pada nyeri sendi sakroiliaka seringkali menyerupai nyeri alih pada nyeri sendi faset maupun nyeri radikular pada HNP sehingga pemetaan yang jelas dibutuhkan untuk membedakan kelainankelainan tersebut. ${ }^{2,-5}$ Dengan mengetahui posisi tubuh yang seringkali mencetuskan dan memperberat nyeri sendi sakroiliaka serta mengetahui pola area nyeri alih maka diagnosis nyeri sendi sakroiliaka dapat ditegakkan.

\section{TUJUAN}

Untuk mengetahui prevalensi pola distribusi nyeri alih dan faktor posisi tubuh yang paling sering mencetuskan atau memperberat nyeri sendi sakroiliaka yang terdiagnosis berdasarkan prosedur blok diagnostik.

\section{METODE}

Penelitian deskriptif potong lintang terhadap pasien dengan nyeri sendi sakroiliaka di Poliklinik Saraf RS Siloam Lippo Village, Tangerang, pada bulan Agustus-Desember 2017. Pasien yang datang dengan keluhan nyeri bokong dilakukan pemeriksaan fisik dan neurologis untuk menyingkirkan kemungkinan nyeri pada sendi faset lumbal, spasme otot, maupun iskialgia. Diagnosis ditegakkan oleh spesialis saraf dengan kriteria inklusi, yakni pasien dapat melokalisir nyeri pada area sendi sakroiliaka dengan tepat (Fortin Finger Test), skala nyeri di atas 7, tidak didapatkan defisit neurologis, dan tes diagnostik injeksi blok intraartikular positif.

Sebelum dilakukan blok diagnostik, pasien dilakukan anamnesis dan pencatatan data antropometri, riwayat pekerjaan, trauma, aktivitas, serta kehamilan. Pasien dinilai posisi yang mencetuskan atau memperberat nyeri sendi sakroiliaka, seperti saat bangun dari posisi tidur, duduk, saat bangun dari duduk, saat berdiri, atau saat berjalan. Pasien juga diminta untuk menunjukkan area/lokasi nyeri selain area sendi sakroiliaka. Prosedur blok diagnostik berupa injeksi lidokain 2\% $1 \mathrm{cc}$ secara intraartikular pada bagian medial inferior sendi sakroiliaka dengan bantuan C-arm. Skala nyeri dievaluasi 15-30 menit pasca-injeksi, ${ }^{3-5}$ jika nyeri menurun $75 \%$, maka pasien dimasukkan ke dalam sampel penelitian.

Data disajikan dalam bentuk frekuensi dan persentase dengan analisis data menggunakan program SPSS versi 20.0. Data nominal dianalisis bivariat menggunakan uji Chi-square atau Fisher.

\section{HASIL}

Didapatkan 114 subjek dengan proporsi lakilaki dan perempuan adalah $30 \%$ dan $70 \%$, serta rerata usia 43 $\pm 11,67$ tahun (Tabel 1). Posisi tubuh yang paling dominan memicu timbulnya nyeri adalah posisi bangun dari duduk $(61,4 \%)$ dan duduk lama 
$(49,1 \%)$. Mayoritas dari subjek melaporkan nyeri hanya pada area sakroiliaka (36\%), diikuti paha bagian posterior $(19,3 \%)$ dan paha lateralis $(11,4 \%)$, seperti pada Tabel 1 dan Gambar 1, sementara lainnya terutama menjalar ke area lain (Tabel 2).

Tabel 1. Karakteristik Gambaran Nyeri Sendi Sakroiliaka $(n=114)$

\begin{tabular}{lc}
\hline Karakteristik & n (\%) \\
\hline Posisi tubuh & \\
- Saat bangun dari posisi tidur & $41(36,0)$ \\
- Duduk & $56(49,1)$ \\
- Saat bangun dari duduk & $70(61,4)$ \\
- Saat berdiri & $32(28,1)$ \\
- Saat jalan & $43(37,7)$ \\
Jumlah area nyeri & \\
- 1 & $41(36,0)$ \\
- 2 & $51(44,7)$ \\
- 3 & $17(14,8)$ \\
- 4 & $2(1,8)$ \\
- 5 & $1(0,9)$ \\
- Lainnya & $2(1,8)$ \\
Area nyeri & \\
- Area sendi sakroiliaka & $41(36,0)$ \\
- Area paha posterior & $22(19,3)$ \\
- Area paha lateralis & $13(11,4)$ \\
- Area panggul & $10(8,8)$ \\
- Area paha lateral dan betis & $4(3,5)$ \\
- Area pangkal paha & $3(2,6)$ \\
\hline
\end{tabular}

\section{PEMBAHASAN}

Dari penelitian ini jumlah penderita nyeri sendi sakroiliaka lebih banyak pada wanita $(70 \%)$ dibandingkan pria $(30 \%)$. Beberapa penelitian terdahulu menyatakan perempuan lebih banyak menderita nyeri sendi sakroiliaka dibanding laki-laki. ${ }^{5}$ Laplante dkk menyebutkan nyeri sendi sakroiliaka sebagai penyebab nyeri kronik yang diderita oleh $83,9 \%$ perempuan. ${ }^{8}$ Salah satu faktor predisposisi ialah kehamilan, ${ }^{9-11}$ seperti dalam penelitian ini sebanyak 79,4\% subjek di kelompok perempuan $(\mathrm{n}=54)$ memiliki riwayat kehamilan.

Rentang usia terbanyak penderita nyeri sendi sakroiliaka pada penelitian ini adalah 40-49 tahun, yang memungkinkan adanya faktor mikrotrauma yang berhubungan dengan aktivitas pekerjaan pada usia tersebut. ${ }^{11-12}$ Pada penelitian ini kelompok pekerja kantoran dengan posisi duduk berdurasi lebih dari 6 jam ditemukan pada 50,5\% subjek. Posisi duduk lama ini dapat mengakibatkan proses inflamasi akibat mikrotrauma repetitif, sehingga menyebabkan peregangan dan kerusakan ligamen utama sendi sakroiliaka. Sampai saat ini belum ada literatur yang menjelaskan keterkaitan antara usia dan jenis pekerjaan dengan pola distribusi dan faktor posisi tubuh pencetus nyeri sendi sakroiliaka.

Pada penelitian ini posisi tubuh yang mencetuskan atau memperberat nyeri sendi sakroiliaka umumnya terjadi pada saat posisi bangun dari posisi duduk $(61,4 \%)$ dan posisi duduk yang lama $(49,1 \%)$. Hal ini dapat berkaitan dengan posisi membungkuk yang berdampak signifikan terhadap stabilitas sendi sakroiliaka. $^{14-15}$

Saat seseorang membungkuk, garis gravitasi berpindah dari posisi normalnya yang cenderung posterior ke titik poros dari tulang inominata yaitu kaput femoris, menuju ke posisi yang lebih anterior dari titik poros. Gravitasi kemudian akan menarik tulang inominata merotasi kaput femoris ke arah anterior. Selanjutnya ketika beban tubuh berpindah ke posisi anterior, basis sakral berpindah semakin jauh dari garis gravitasi pada bidang horizontal, meningkatkan gaya pengungkit pada ligamentum sakroiliaka. Akibatnya, otot hamstring, abdominal, dan otot ekstensor panggul lainnya menerima tekanan yang cukup berat ketika otot-otot tersebut berusaha menahan rotasi anterior yang lebih jauh dari tulang inominata yang melawan gravitasi, sehingga otot tersebut dapat mengalami sprain dan robek. Saat otot-otot tersebut berusaha berkontraksi menarik tulang inominata ke arah posterior melawan gravitasi dan beban tubuh mendorong sakrum ke arah anterior, ligamen-ligamen yang menahan pergerakan tersebut dapat mengalami regangan juga. ${ }^{14}$

Sebagian besar pasien dengan nyeri punggung dengan etiologi disfungsi sendi sakroiliaka menunjukkan adanya malposisi pelvis akibat pergeseran anterior unilateral dari pelvis. Pergeseran ini dapat diperparah ketika berdiri, duduk, atau berjalan yang 


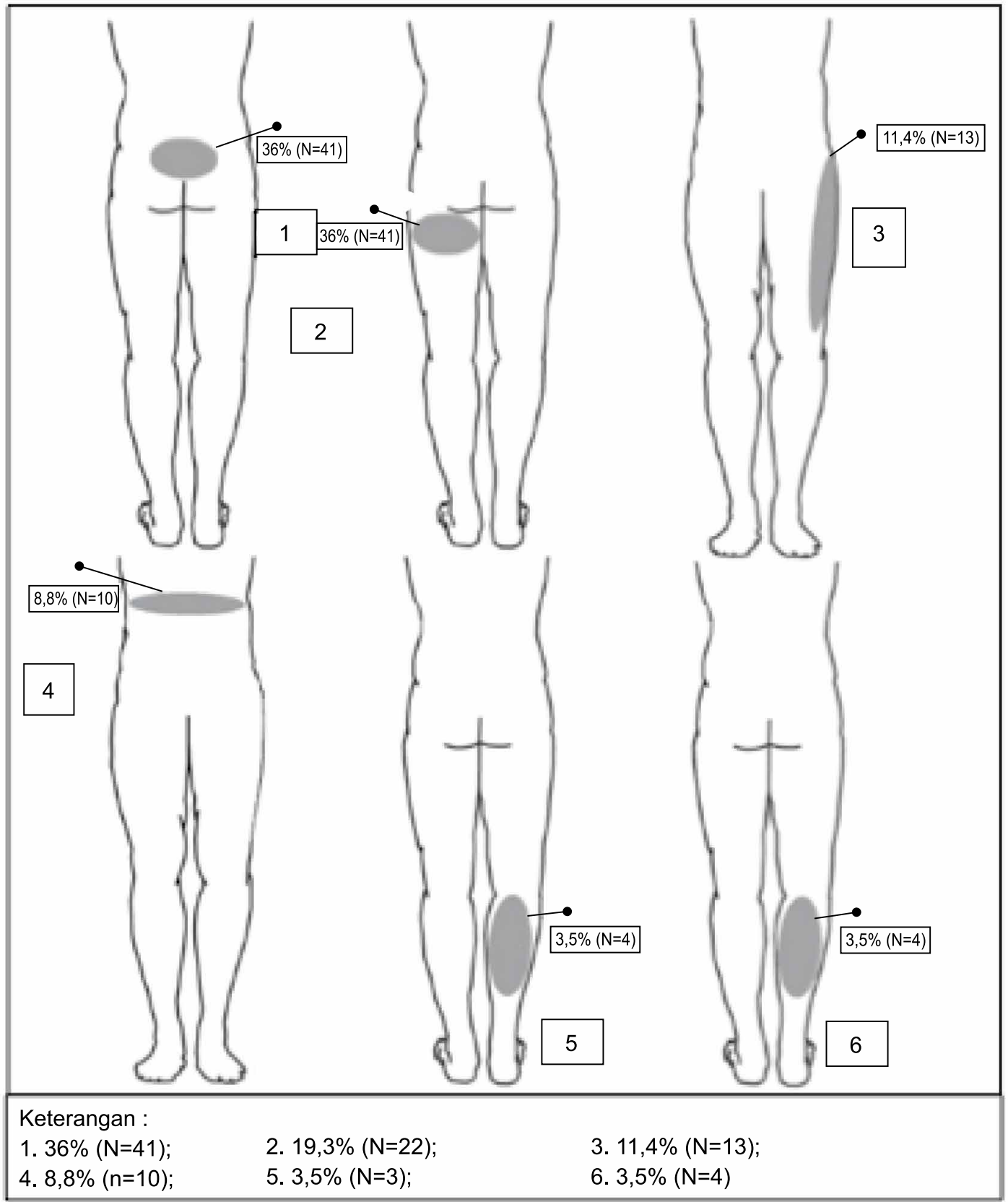

Gambar 1. Pola Distribusi Nyeri

menjelaskan nyeri saat posisi berdiri dan bangun dari tidur. Peningkatan ko-aktivasi dari otot-otot pinggul dan tungkai juga dikaitkan dengan nyeri punggung bawah pada pasien dengan posisi tubuh berdiri. Posisi duduk yang ergonomis sendiri dapat menimbulkan pergeseran posterior yang menstabilkan pelvis dan mengurangi nyeri punggung pada disfungsi sendi sakroiliaka. ${ }^{16-17}$

Posisi yang mencetuskan nyeri atau memperberat nyeri pada nyeri sendi sakroiliaka berbeda dengan posisi yang mencetuskan nyeri sendi faset lumbal yang terutama dapat dimunculkan dengan posisi fleksi. ${ }^{18}$ Penyebab nyeri pinggang bawah lainnya, seperti spasme otot meskipun dapat dicetuskan oleh posisi bangun dari duduk tetapi pada umumnya tidak disertai nyeri alih. ${ }^{15}$

Selain posisi tubuh, penelitian ini juga meneliti area nyeri lainnya yang dirasakan pasien. Area nyeri yang dirasakan timbul bersamaan dengan nyeri sendi sakroiliaka sering disebut sebagai nyeri alih. Gangguan muskuloskeletal lain seperti gangguan sendi faset memiliki manifestasi klinis yang identik 
Tabel 2. Area Distribusi Nyeri

\begin{tabular}{lc}
\hline Distribusi Nyeri & n (\%) \\
\hline Area sendi sakroiliaka & $41(36)$ \\
Area sendi sakroiliaka dan paha posterior & $22(19,3)$ \\
Area sendi sakroiliaka dan paha lateralis & $13(11,4)$ \\
Area sendi sakroiliaka dan panggul & $10(8,8)$ \\
Area sendi sakroiliaka, paha posterior, dan betis & $4(3,5)$ \\
Area sendi sakroiliaka dan pangkal paha & $3(2,6)$ \\
Area sendi sakroiliaka dan betis & $3(2,6)$ \\
Area sendi sakroiliaka, paha posterior, dan panggul & $3(2,6)$ \\
Area sendi sakroiliaka, pangkal paha, dan betis & $3(2,6)$ \\
Area sendi sakroiliaka, paha posterior, dan panggul & $2(1,7)$ \\
Area sendi sakroiliaka, paha lateral, dan panggul & $2(1,7)$ \\
Area paha posterior & $1(0,9)$ \\
Area paha posterior dan betis & $1(0,9)$ \\
Area sendi sakroiliaka, paha posterior, dan paha lateral & $1(0,9)$ \\
Area sendi sakroiliaka, paha posterior, dan panggul & $1(0,9)$ \\
Area sendi sakroiliaka, paha lateral, dan panggul & $1(0,9)$ \\
Area sendi sakroiliaka, paha posterior, paha lateral, dan panggul & $1(0,9)$ \\
Area sendi sakroiliaka, paha posterior, paha lateral, dan betis & $1(0,9)$ \\
Area sendi sakroiliaka, paha posterior, paha lateral, panggul, dan betis & $1(0,9)$ \\
\hline
\end{tabular}

dengan nyeri sendi sakroiliaka sehingga sering sulit dibedakan. Pemetaan area nyeri alih pada nyeri sendi sakroiliaka ini memberikan tambahan data untuk mempermudah dalam diagnosis.

Hasil penelitian menunjukkan terdapat 31,6\% yang hanya mengeluhkan 1 area nyeri di sakroiliaka, disertai paha sisi posterior $(19,3 \%)$ dan sisi lateral $(11,4 \%)$. Hasil ini menunjukkan tidak semua pasien dengan disfungsi sendi sakroiliaka mengeluhkan nyeri alih, seperti Slipman dkk yang dalam penelitiannya menyebutkan $12 \%$ subjek mengeluh nyeri area sendi sakroiliaka saja. ${ }^{15}$ Terdapat $44,7 \%$ subjek yang menyebutkan nyeri pada 2 area, yang menunjukkan umumnya nyeri alih dikeluhkan hanya pada 1 area. Nyeri alih pada 1 area juga didapatkan pada nyeri sendi facet lumbal. ${ }^{14}$

Slipman dkk menemukan area posterior sebagai area nyeri alih paling dominan (30\%), seperti penelitian ini, namun Laplante dkk mendapatkan nyeri alih lebih banyak pada daerah lipat paha $(50 \%){ }^{8,17}$ Hal ini menunjukkan masih dibutuhkannya penelitian yang lebih mendalam tentang area nyeri alih pada pasien dengan nyeri sendi sakroiliaka dengan area posterior sebagai area terbanyak, berbeda dengan Laplante dkk. ${ }^{8,15}$

Keterbatasan dalam penelitian ini adalah sampel yang diambil berasal dari satu fasilitas kesehatan sehingga sebaran dan pola aktivitas subjek penelitian kurang beragam, sehingga diperlukan penelitian lebih lanjut dengan jumlah sampel yang lebih besar dan bervariasi.

\section{KESIMPULAN}

Faktor yang paling dominan mencetuskan atau dapat memperberat nyeri sendi sakroiliaka adalah posisi bangun dari duduk dan posisi duduk yang lama. Adapun pola distribusi nyeri alih adalah daerah paha sisi posterior dan lateral. Hal ini dapat mendukung klinis penegakan diagnosis nyeri akibat disfungsi sendi sakroiliaka.

\section{DAFTAR PUSTAKA}

1. Gupta S, Hameed H, Diwan S. A systematic evaluation of prevalence and diagnostic accuracy of sacroiliac joint intervention. Pain Physician. 2012;15:E305-44.

2. Cohen SP, Chen Y, Neufeld NJ. Sacroiliac joint pain: a comprehensive review of epidemiology, diagnosis, and treatment. Expert Rev Neurother. 2013;13(1):99116. 
3. Cher D, Polly D, Berven S. Sacroiliac joint pain: burden of disease. Med Devices (Auckl). 2014;7:7381.

4. Todorov P, Nestorova R, Batalov A. Diagnostic value of musculoskeletal ultrasound in patients with low back pain - a review of literature. Med Ultrason. 2018;20(1): 80-7.

5. Moscote-Salazar LR, Alvis-Miranda HR, Joaquim AF, Amaya-Quintero J, Padilla-Zambrano HS, Agrawal A. Sacroiliac pain: a clinical approach for the neurosurgeon. J Neurosci Rural Pract. 2017;8(4):6227.

6. Holmes SL, Cohen SP, Cullen MFL, Kenny CD, Wain HJ, Davis S. Sacroiliac joint pain. Dalam: Hayek SM, Shah BJ, Desai MJ, Thomas C, editor. Pain medicine: an interdisciplinary case-based approach. New York: Oxford University Press; 2015. h. 160-82.

7. Kothari G, Berkwits L, Batson JP, Furman MB. Sacroiliac intraarticular joint injections, posterior approach, inferior entry. Dalam: Furman MB, Lee TS BL, editor. Atlas of image-guided spinal procedures. Philadelphia: Elsevier. 2014. h. 79-85.

8. Laplante BL, Ketchum JM, Saullo TR, Depalma M. Multivariable analysis of the relationship between pain referral pattern and the source of chronic low back pain. Pain Physician. 2012;15(2):171-8.

9. Clark SM, Lindsey RW. Low back pain and pelvic girdle pain in pregnancy abstract. JAAOS. 2015;23(9):539-49.

10. Munro A, George RB, Chorney J, Snelgrove-Clarke E, Rosen NO. Prevalence and predictors of chronic pain in pregnancy and postpartum. J Obstetrics and Gyn Canada. 2017;39(9):734-41.
11. Irwin RW, Watson T, Minick RP, Ambrosius WT. Age, body mass index, and gender differences in sacroiliac joint. Am J Physical Med Rehabilitation. 2007;86(1):37-44.

12. Manchikanti L, Singh V, Falco FJE, Benyamin RM, Hirsch JA. Epidemiology of low back pain in adults. Neuromodulation: Technology at the Neural Interface. 2014;17(S2):3-10.

13. Kurosawa D, Murakami E. A diagnostic scoring system for sacroiliac joint pain originating from the posterior ligament. Pain Med. 2017;18(2):228-38.

14. Taheri A, Moallemy A, Dehghanian A, Vatankhah P. Evaluation of the relationship between age, gender, body mass index, and lumbar facet joint pain. Indian J Pain. 2016;30(1):19-22.

15. Yoo W. Effects of individual strengthening exercises for the stabilization muscles on the nutation torque of the sacroiliac joint in a sedentary worker with nonspecific sacroiliac joint pain. J Phys Ther Sci. 2015;27(1):313-4.

16. Cho B, Yoon J. The effect of gait training with shoe inserts on the improvement of pain and gait in sacroiliac joint patients. J Phys Ther Sci. 2015;27(8):2469-71.

17. Slipman CW, Jackson HB, Lipetz JS, Chan KT, Lenrow D, Vresilovic EJ, dkk. Sacroiliac joint pain referral zones. Archives of physical medicine and rehabilitation. 2000;81(3):334-8.

18. Kurosawa D, Murakami E. Referred pain location depends on the affected section of the sacroiliac joint. Eur Spine J. 2015;24(3):521-7. 